\title{
Gas/particle partitioning and global distribution of polycyclic aromatic hydrocarbons - A modelling approach
}

\author{
Gerhard Lammel $^{\mathrm{a}, \mathrm{b}, *}$, Aissa M. Sehili ${ }^{\mathrm{a}, \mathrm{c}}$, Tami C. Bond ${ }^{\mathrm{d}}$, Johann Feichter ${ }^{\mathrm{a}}$, Hartmut Grassl ${ }^{\mathrm{a}, \mathrm{c}}$ \\ ${ }^{a}$ Centre for Marine and Atmospheric Sciences, Max Planck Institute for Meteorology, Bundesstr. 53, 20146 Hamburg, Germany \\ ${ }^{\mathrm{b}}$ Masaryk University, Research Centre for Environmental Chemistry and Ecotoxicology, Kamenice 3, 62500 Brno, Czech Republic \\ ${ }^{\mathrm{C}}$ Centre for Marine and Atmospheric Sciences, University of Hamburg, Meteorological Institute, Bundesstr. 55, 20146 Hamburg, Germany \\ ${ }^{\mathrm{d}}$ University of Illinois, Department of Civil and Environmental Engineering, 250 N Mathews Ave., Urbana, IL 61801, USA
}

\section{A R T I C L E I N F O}

\section{Article history:}

Received 24 November 2008

Received in revised form 4 February 2009

Accepted 6 February 2009

Available online 10 March 2009

\section{Keywords:}

Polycyclic aromatic hydrocarbons

Gas-particle partitioning

Long-range transport

Multicompartmental modelling

\begin{abstract}
A B S T R A C T
The global atmospheric distribution and long-range transport (LRT) potential of three polycyclic aromatic hydrocarbons (PAH) - anthracene, fluoranthene and benzo[a]pyrene - are studied. The model used is a global aerosol-chemistry-transport-model, which is based on an atmospheric general circulation model. The model includes an in-built dynamic aerosol model coupled to two-dimensional surface compartments. Several parameterisations of gas/particle partitioning and different assumptions of degradation in the aerosol particulate phase were tested.

PAHs are mostly distributed in the source regions but reach the Arctic and the Antarctic. The Canadian Arctic is predicted to be significantly less affected by mid-latitude PAH emissions than the European Arctic. Re-volatilisation is significant for semivolatile PAHs. Accumulation of semivolatile PAHs in polar regions, however, is not indicated. The model study suggests that gas/particle partitioning in air drastically influences the atmospheric cycling, the total environmental fate (e.g. compartmental distributions) and the LRT potential of the substances studied. A parameterisation which calculates the gas/particle partitioning assuming absorption into organic matter and adsorption to black carbon (soot) agrees best with the observations at remote sites. The study provides evidence that the degradation in the particulate phase must be slower than that in the gas-phase. The predicted concentrations of the semivolatile PAHs anthracene and fluoranthene in near-ground air at remote sites in mid and high northern latitudes are in line with measured concentrations, if adsorption of the substances to soot combined with absorption in particulate organic matter is assumed to determine gas/particle partitioning, but cannot be explained by adsorption alone (Junge-Pankow parameterisation of gas/particle partitioning). The results suggest that PAHs absorbed in the organic matrix of particulate matter is shielded from the gas-phase.
\end{abstract}

(c) 2009 Elsevier Ltd. All rights reserved.

\section{Introduction}

Among atmospheric trace chemical substances, PAHs probably form the class most harmful to human health (WHO, 2003, besides others). Hence, PAHs have been added to the list of persistent organic pollutants (POPs) to be regulated under the POPs protocol of the convention on long-range transboundary air pollution and are also covered by the convention for the protection of the marine environment of the north-east Atlantic (OSPAR convention). PAHs undergo long-range transport (LRT) and reach pristine areas in high altitudes and latitudes (e.g. Macdonald et al., 2000; Fernández et al., 2002). PAH concentrations in the Arctic are determined by LRT, as local sources are negligible. Concentrations in air are

\footnotetext{
* Corresponding author. Present address: Now at Max Planck Institute for Chemistry, J.-J.-Becher-Weg 27, 55128 Mainz, Germany. Tel.: +49 6131305 233; fax +496131305436

E-mail address: lammel@mpch-mainz.mpg.de (G. Lammel).
}

influenced by photochemical degradation and other atmospheric removal processes (deposition) and the source variability. Strong seasonalities result in both source and remote areas (EMEP, 2007). The fate of PAHs in the atmosphere has been the subject of case studies (e.g. Cotham and Bidleman, 1995; Tsapakis and Stephanou, 2005). The distribution and environmental fate of PAHs have been studied by regional modelling (Prevedouros et al., 2005) and also globally (but considering emissions in only one region; Sehili and Lammel, 2007). These studies focused on few substances, among them benzo[a]pyrene (BAP), which is considered as an important substance for toxicity and a criteria pollutant in many countries.

The semivolatility and persistence of PAHs imply that two major processes of environmental cycling could be significant: gas/ particle partitioning in air (Franklin et al., 2000; Lohmann and Lammel, 2004) and re-volatilisation from ground surfaces (multihopping; Wania and Mackay, 1993; Semeena and Lammel, 2005). These processes are key for understanding the distribution, 
transport pathways and environmental fate of PAHs. The process of $\mathrm{PAH}$ gas/particle partitioning is still not understood (Lohmann and Lammel, 2004; Galarneau et al., 2006). Large mass fractions are found in soils, ocean and sediments, more than in air (Bouchez et al., 1996), and cycling of PAHs includes gas-exchange at surfaces, such as sea (Dickhut and Gustafson, 1995), vegetation (McLachlan, 1999) and soils (Sweetman et al., 2005). Surface/air exchange was one of the foci of a previous modelling study (Sehili and Lammel, 2007) and large areas were found to have seasonal net-volatilisation for fluoranthene (FLT, a semivolatile PAH), much less than for BAP, both emitted in Europe and Russia. It is therefore essential to use a multicompartment (multimedia) model to describe semivolatile PAH behaviour in air. We use a multicompartment chemistry-atmospheric transport model (Semeena et al., 2006; Sehili and Lammel, 2007).

The purpose of this study was to describe the atmospheric fate of PAH as influenced by chemical transformation and gas/particle partitioning in atmospheric aerosols on the global scale. To our knowledge this is the first such study. Three PAHs of varying molecular weight were chosen, two of them semivolatile and several scenarios were tested.

\section{Methods}

Substances studied: One 3-, 4- and 5-ring PAH, anthracene (ANT), fluoranthene (FLT), and benzo[a]pyrene (BAP), were selected for this study as these are significant in the environment and cover a range of physico-chemical properties. The species and their degradation rates are listed in Table 1. Particle-associated PAHs rapidly react with ozone (Pöschl et al., 2001; Schauer et al., 2003; Tsapakis and Stephanou, 2003). On the other hand, observations in ambient air suggest that the reactivity of PAHs may be reduced when they are sorbed to aerosol particles (relative to their behaviour in the gas-phase), this is in contrast to the findings of laboratory studies. This discrepancy may be explained by the influence of the particulate matter matrix on degradation kinetics (Franklin et al., 2000; Pöschl et al., 2001), e.g., rate coefficients for the reaction with the hydroxyl radical in the range $k_{\mathrm{OH}}=(0.3-4) \times$ $10^{-12} \mathrm{~cm}^{3}$ molec $^{-1} \mathrm{~s}^{-1}$ were determined for ANT, FLT and BAP sorbed to carbonaceous particles (diesel and graphite) (Estève et al., 2006), this is about one order of magnitude lower than the rate coefficients of the gas. No such coefficients, however, are available for any other type of particulate matter.

To investigate the sensitivity of the atmospheric fate to the reactivity of PAHs sorbed to atmospheric aerosol particles, different rates were assumed under the various scenarios: Second-order rate coefficients (in $\mathrm{cm}^{3}$ molec ${ }^{-1} \mathrm{~s}^{-1}$ ) with the atmospheric oxidants ozone, $k_{\mathrm{O}_{3}}$, hydroxyl radical ( $k_{\mathrm{OH}}$, day-time only) and nitrate radical $\left(k_{\mathrm{NO}_{3}}\right.$, night-time only) were set to zero for molecules sorbed to particles under the AD (adsorption-only) and OB (absorption into organic matter and adsorption to black carbon) scenarios, but non-zero rate coefficients, equal to the gas-phase rate coefficients in the case of ANT and FLT, less in the case of BAP, were adopted for both phases under the DP (degradation in the particulate phase) scenario (Table 1). Three-dimensional monthly mean oxidant fields of $\mathrm{OH}, \mathrm{H}_{2} \mathrm{O}_{2}, \mathrm{O}_{3}$ and $\mathrm{NO}_{2}$ are prescribed from calculations using a comprehensive air chemistry-transport model (Horowitz et al., 2003).

Emission estimates: No global emissions of PAHs had been compiled previously. Emission estimates for this study were based on combustion technologies (mass of fuel burnt basis; Bond et al., 2004) for stationary and mobile sources and represent 1996 emissions. Mobile sources on sea (ships) are ignored. No PAH emission factor was available for some technologies, such as particular kinds of coal burning. In these cases, PAH emission factors were scaled from technologies that were deemed to be similar according to the $\mathrm{PM}_{1}$ emission factor. PAHs and sub-micrometer carbonaceous particles have common sources: both are products of incomplete combustion and can be formed within the same chain of molecular and supra-molecular reactions (Finlayson-Pitts and Pitts, 2000). Good agreement between PAH emission distribution and aerosol optical depth, which is also linked to sub-micrometer aerosols, was observed on a regional basis (for China; Zhang et al., 2007). The scaling of PAHs with sub-micrometer particles introduces some uncertainty, particularly with regard to spatial distribution. The emission estimates are intended for large-scale modelling and analysis of long-range transport far from emission areas, but are not meant to provide highly resolved high-accuracy distributions. On regional and annual scales the results compare quite well with more detailed emission inventories for BAP. More information on the methodology, validation and geographical distributions of the emissions are available in the Supplementary material.

Table 1

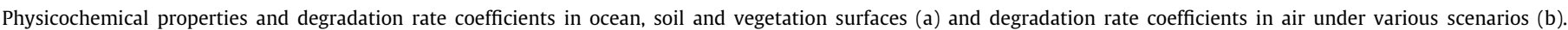

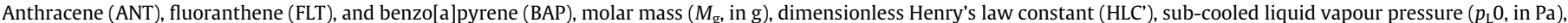

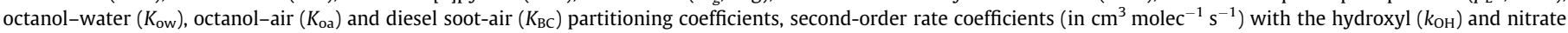

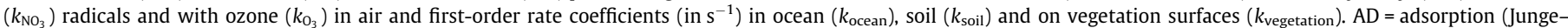

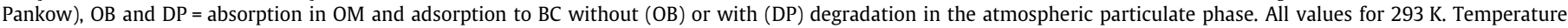
dependencies were considered as far as available.

\begin{tabular}{|c|c|c|c|c|c|c|c|c|c|}
\hline $\mathrm{a}$ & $M_{\mathrm{g}}$ & $\log \mathrm{HLC}^{\prime a}$ & $\log p_{\mathrm{L}}^{0 \mathrm{a}}$ & $\log K_{\text {ow }}{ }^{\mathrm{a}}$ & $\log K_{\text {oa }}{ }^{\mathrm{a}}$ & $\log K_{\mathrm{BC}}{ }^{\mathrm{a}}$ & $k_{\text {ocean }}{ }^{\mathrm{c}}$ & $k_{\text {soil }}{ }^{\mathrm{c}}$ & $k_{\text {vegetation }}{ }^{\mathrm{c}}$ \\
\hline ANT & 178 & -3.0 & -1.4 & 4.6 & 7.7 & 9.5 & $3.1 \times 10^{-8}$ & $2.2 \times 10^{-8}$ & $2.2 \times 10^{-8}$ \\
\hline FLT & 202 & -3.3 & -2.2 & 5.1 & 8.6 & 10.5 & $3.1 \times 10^{-8}$ & $2.2 \times 10^{-8}$ & $2.2 \times 10^{-8}$ \\
\hline BAP & 252 & -4.7 & -5.2 & 5.9 & 11.1 & 13.0 & $3.1 \times 10^{-8}$ & $2.2 \times 10^{-8}$ & $2.2 \times 10^{-8}$ \\
\hline $\mathrm{b}$ & Scenario & Partitioning $^{\mathrm{b}}$ & & & $k_{\mathrm{OH}}{ }^{\mathrm{c}}$ particle & $k_{\mathrm{NO}_{3}}{ }^{\mathrm{C}}$ gas & $k_{\mathrm{NO}_{3}}{ }^{\mathrm{C}}$ particle & $k_{\mathrm{NO}_{3}}{ }^{\mathrm{C}}$ gas & $k_{\mathrm{NO}_{3}}{ }^{\mathrm{C}}$ particle \\
\hline ANT & AD & JP & & & 0 & $1.2 \times 10^{-12}$ & 0 & $9.0 \times 10^{-19}$ & 0 \\
\hline ANT & OB & LL & & & 0 & $1.2 \times 10^{-12}$ & 0 & $9.0 \times 10^{-19}$ & 0 \\
\hline ANT & DP & LL & & & $1.9 \times 10^{-10}$ & $1.2 \times 10^{-12}$ & $1.2 \times 10^{-12}$ & $9.0 \times 10^{-19}$ & $9.0 \times 10^{-19}$ \\
\hline FLT & $A D$ & JP & & & 0 & $2.5 \times 10^{-12}$ & 0 & $4.0 \times 10^{-19}$ & 0 \\
\hline FLT & OB & LL & & & 0 & $2.5 \times 10^{-12}$ & 0 & $4.0 \times 10^{-19}$ & 0 \\
\hline FLT & DP & LL & & & $5.0 \times 10^{-11}$ & $2.5 \times 10^{-12}$ & $2.5 \times 10^{-12}$ & $4.0 \times 10^{-19}$ & $4.0 \times 10^{-19}$ \\
\hline BAP & $A D$ & JP & & & 0 & $5.4 \times 10^{-11}$ & 0 & $2.6 \times 10^{-17}$ & 0 \\
\hline BAP & OB & LL & & & 0 & $5.4 \times 10^{-11}$ & 0 & $2.6 \times 10^{-17}$ & 0 \\
\hline BAP & DP & LL & & & $3.7 \times 10^{-11}$ & $5.4 \times 10^{-11}$ & $5.4 \times 10^{-11}$ & $2.6 \times 10^{-17}$ & $2.6 \times 10^{-17}$ \\
\hline
\end{tabular}

a Lohmann and Lammel (2004).

b According to an empirical relationship (JP; Junge, 1977; Pankow, 1987) or determined by a combination of absorption into organic matter and adsorption onto BC (LL; Lohmann and Lammel, 2004), respectively.

c Finlayson-Pitts and Pitts (2000) and Klöpffer and Wagner (2007). 
The emissions were distributed on a $1^{\circ} \times 1^{\circ}$ grid according to proxies (land cover, fire counts, rural population and agricultural land). The global annual emission fluxes are estimated to $2754 \mathrm{t}$ $\left(18.4 \mu \mathrm{g} \mathrm{m}^{-2}\right.$ land area) for ANT, $11,550 \mathrm{t}\left(77.0 \mu \mathrm{g} \mathrm{m}^{-2}\right)$ for FLT and $3701 \mathrm{t}\left(24.7 \mu \mathrm{g} \mathrm{m}^{-2}\right)$ for BAP. About two thirds of the emissions are located in the northern hemisphere $(73 \%, 66 \%$ and $63 \%$ for ANT, FLT and BAP, respectively) and only 5.5\%, 5.1\% and 3.5\%, respectively, are emitted north of $50^{\circ} \mathrm{N}$. Temporal variability (e.g. seasonality) of emission sources is neglected. The distributions are shown in the Supplementary material.

Model used: The model is based on the atmosphere general circulation model ECHAM5 (Roeckner et al., 2006) with simplified atmospheric chemistry (Feichter et al., 1996) and an aerosol module (HAM; Stier et al., 2005). HAM takes into account the aerosol components sulphate, black carbon, organic carbon (primary and secondary), mineral dust and seasalt (more details are given in the Supplementary material). The time step used was $30 \mathrm{~min}$ and the horizontal resolution $\approx 2.8^{\circ} \times 2.8^{\circ}$ with 19 levels in the vertical between 1000 and $10 \mathrm{hPa}$. Two-dimensional ground compartments are coupled (multicompartment model; Semeena et al., 2006), i.e. single layers of vegetation and soil on continents or ocean. The PAHs behave similarly in the ground compartments upon deposition from gas or particulate phase. Uptake of PAHs into leaves and other parts of vegetation is ignored. Immediate gas-exchange with air is assumed, which ignores retardation which may take up to several months (McLachlan, 1999). Therefore, the model

Table 2

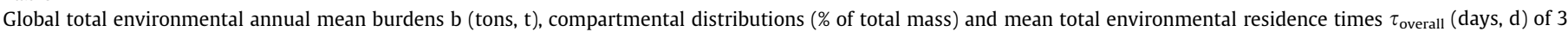

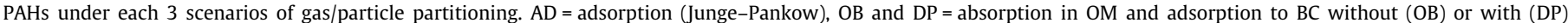
degradation in the atmospheric particulate phase. Mean of years 6-10 of the simulation. The global emission flows, $F_{\text {em }}\left(t\right.$ year $\left.{ }^{-1}\right)$, are given in brackets for comparison.

\begin{tabular}{|c|c|c|c|c|c|c|c|}
\hline Substance & Scenario & Total (t) & Air (\%) & Soil (\%) & Vegetation (\%) & Ocean (\%) & $\tau_{\text {overall }}(\mathrm{d})$ \\
\hline ANT & $\mathrm{AD}$ & 73 & 0.8 & 49 & 49 & 0.9 & 10 \\
\hline \multirow[t]{2}{*}{$(2754)$} & ОВ & 1361 & 2.8 & 45 & 46 & 5.9 & 181 \\
\hline & $\mathrm{DP}$ & 32 & 0.3 & 49 & 50 & 0.9 & 4.2 \\
\hline FLT & $\mathrm{AD}$ & 288 & 1.3 & 48 & 49 & 1.8 & 9.1 \\
\hline \multirow[t]{2}{*}{ (11550) } & OB & 5445 & 3.6 & 42 & 43 & 11.1 & 172 \\
\hline & DP & 155 & 0.9 & 48 & 49 & 2.0 & 4.9 \\
\hline BAP & $\mathrm{AD}$ & 530 & 1.3 & 46 & 47 & 5.7 & 52 \\
\hline \multirow[t]{2}{*}{ (3701) } & OB & 819 & 2.5 & 44 & 46 & 7.8 & 81 \\
\hline & $\mathrm{DP}$ & 24 & 0.3 & 47 & 50 & 2.8 & 2.4 \\
\hline
\end{tabular}
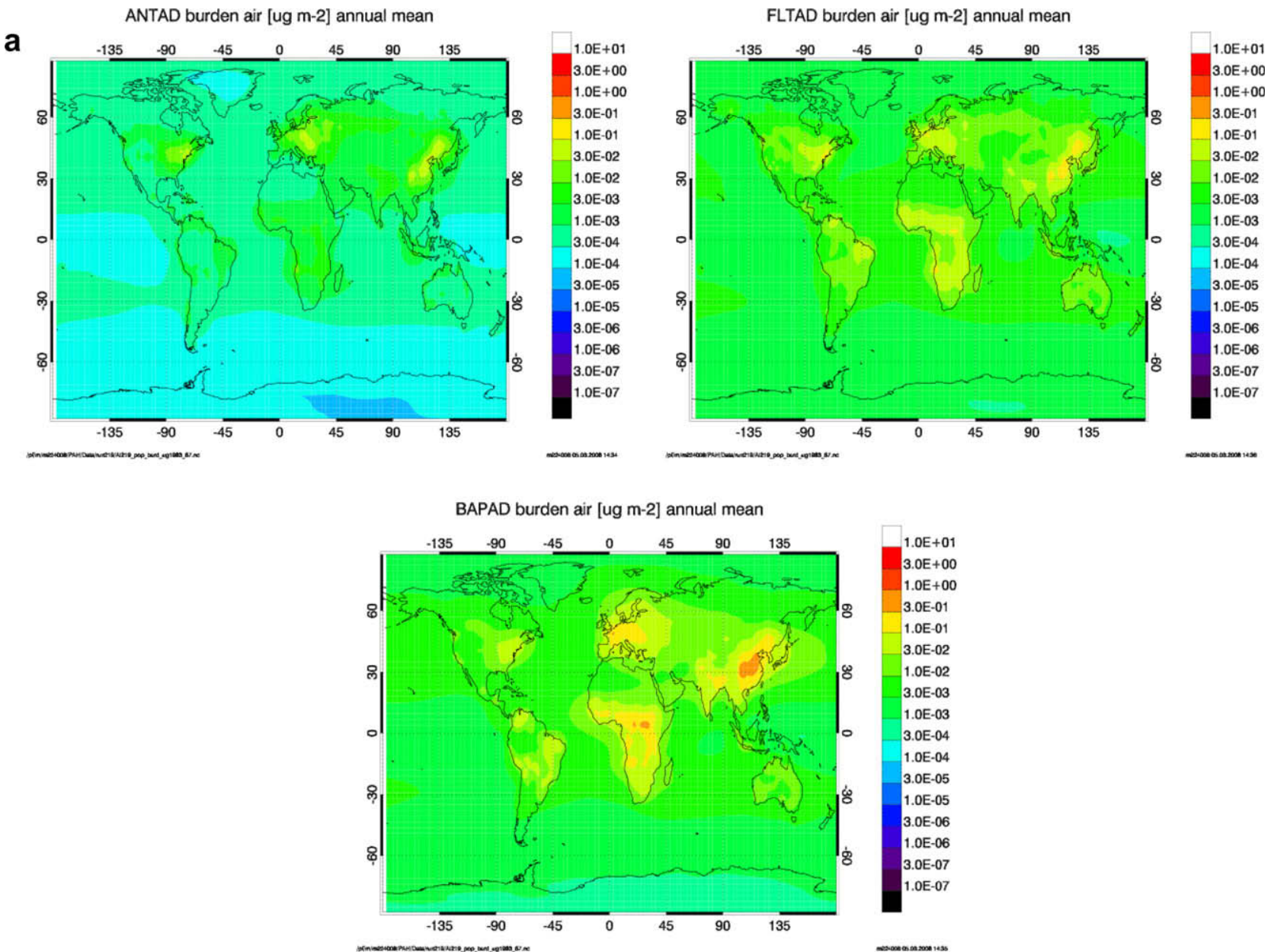

Fig. 1. Global annual mean atmospheric burdens $\left(\mu \mathrm{g} \mathrm{m}^{-2}\right)$ of ANT, FLT and BAP under the AD (a), OB (b) and DP (c) scenarios. Mean of years 6-10 of the simulation. 

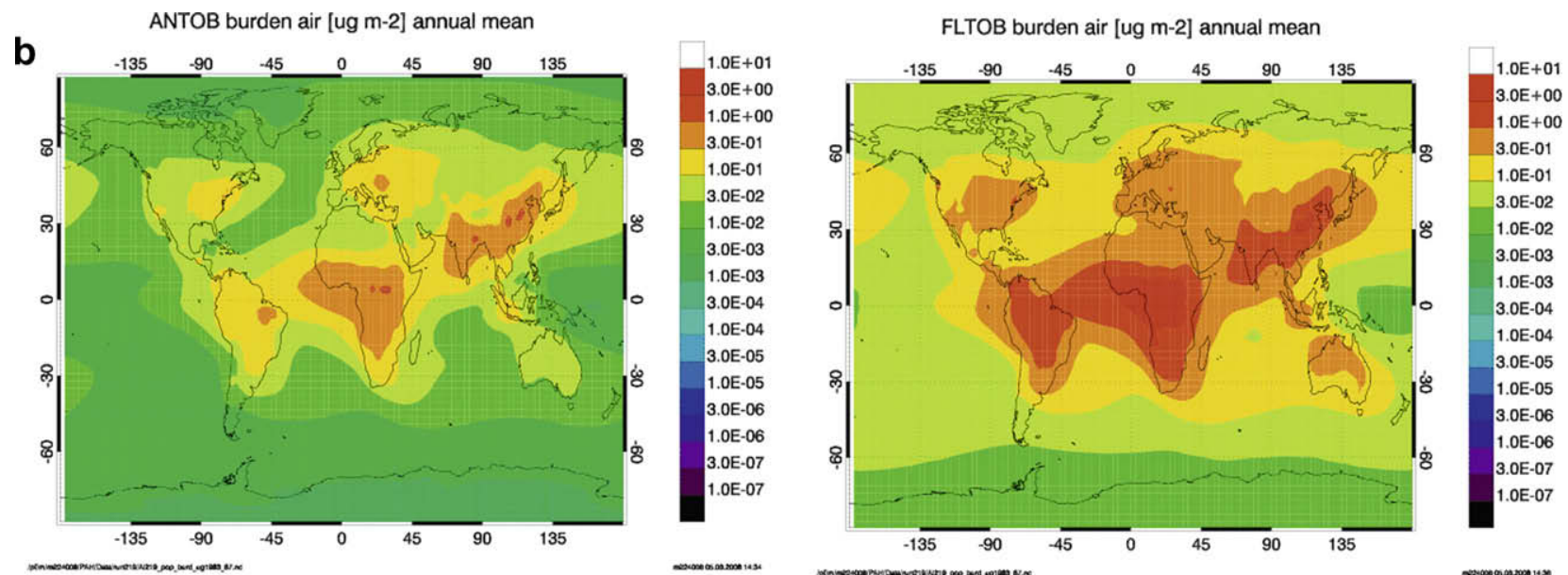

BAPOB burden air [ug $\mathrm{m}-2$ ] annual mean

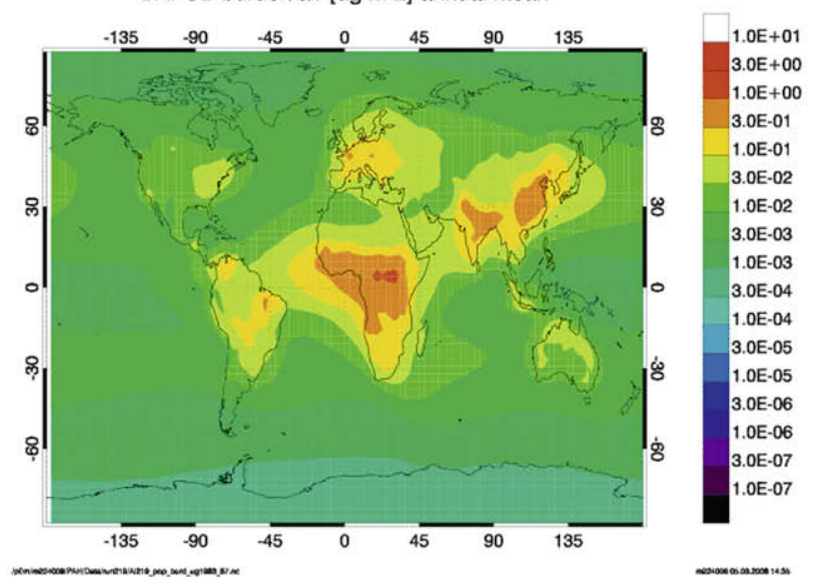

Fig. 1 (continued)

tends to underestimate the response time of the vegetation compartment to changes of air pollution. This will be of minor significance for this analysis, however, because no interpretation of temporally high-resolved ( $<1$ month) model output is made. No ice compartment is included in the model. Instead, all land area which is not vegetation-covered is represented as 'soil' and the entire ocean is exposed to the atmosphere. The model includes a well mixed surface layer ocean, taken from a 3D ocean general circulation model. Substance is lost to the deep sea as a consequence of the seasonal variation of the surface layer depth.

The model simulations were initialized by sea-surface temperature distributions according to present-day climate and run over 10 years.

Description of gas/particle partitioning: The often used assumption that adsorption alone determines the gas/particle partitioning of organics is not justified considering the various kinds of interactions between gaseous and condensed phase substances (Roeckner et al., 2006). Insufficient data are available, however, to describe PAH gas/particle interactions according to theory. Lipophilic substances absorb in the organic matrix of particulate matter (OM; Finizio et al., 1997) and PAHs show a special affinity toward particles rich in carbon, such as soot or black carbon (BC; e.g. Dachs and Eisenreich, 2000; Finlayson-Pitts and Pitts, 2000). Based on a review of gas/particle partitioning of PAHs, a parameterisation for LRT modelling was recommended (Lohmann and Lammel, 2004). It determines the partitioning coefficient, $K_{\mathrm{p}}$, using a combination of absorption into organic matter (using the octanol-air partition- ing coefficient, $K_{\text {oa }}$; e.g. Harner and Bidleman, 1998) and adsorption onto BC. BC properties are approximated by diesel soot:

$K_{\mathrm{p}}=10^{-12}\left[\left(f_{\mathrm{oM}} / \rho_{\text {oct }}\right) K_{\text {oa }}+\left(f_{\mathrm{BC}} / \rho_{\text {oct }}\right) K_{\mathrm{sa}}\right]$

where $K_{\mathrm{p}}$ (in $\mathrm{m}^{3} \mu \mathrm{g}^{-1}$ ) $K_{\mathrm{oa}}, K_{\mathrm{sa}}$ are the partitioning coefficients between octanol, soil and air, $f_{\mathrm{OM}}$ and $f_{\mathrm{BC}}$ the organic matter and black carbon mass fractions, and $\rho_{\text {oct }}$ the density of octanol. The substance mass fraction which is sorbed to particles in air, $\theta$, is defined as:

$\theta=\left[1+1 /\left(K_{\mathrm{p}} c_{\mathrm{TSP}}\right)\right]^{-1}$

( with $=c_{\mathrm{TSP}}$ total suspended particulate concentration).

In this study this parameterization is used to study the atmospheric fate of PAHs on the global scale. This model is also compared with a common alternative, which describes partitioning according to an empirical relationship found by Junge, later extended by Pankow (Junge, 1977; Pankow, 1987):

$\theta=c(S / V) /\left[c(S / V)+p_{\mathrm{L}}\right]$

This model relies on a constant, $c=17.2 \mathrm{~Pa} \mathrm{~cm}$, the particulate matter surface concentration $\left(S / V\right.$ in $\left.\mathrm{cm}^{-2} / \mathrm{cm}^{-3}\right)$ and the temperature dependent vapour pressure of the sub-cooled liquid $\left(p_{\mathrm{L}}\right.$ in $\mathrm{Pa}$ ).

In the model experiments, all PAH emissions were released into air in the particulate phase. Partitioning between gas and particulate matter phase takes place upon emission and during every subsequent time step. Each phase is transported independently. 

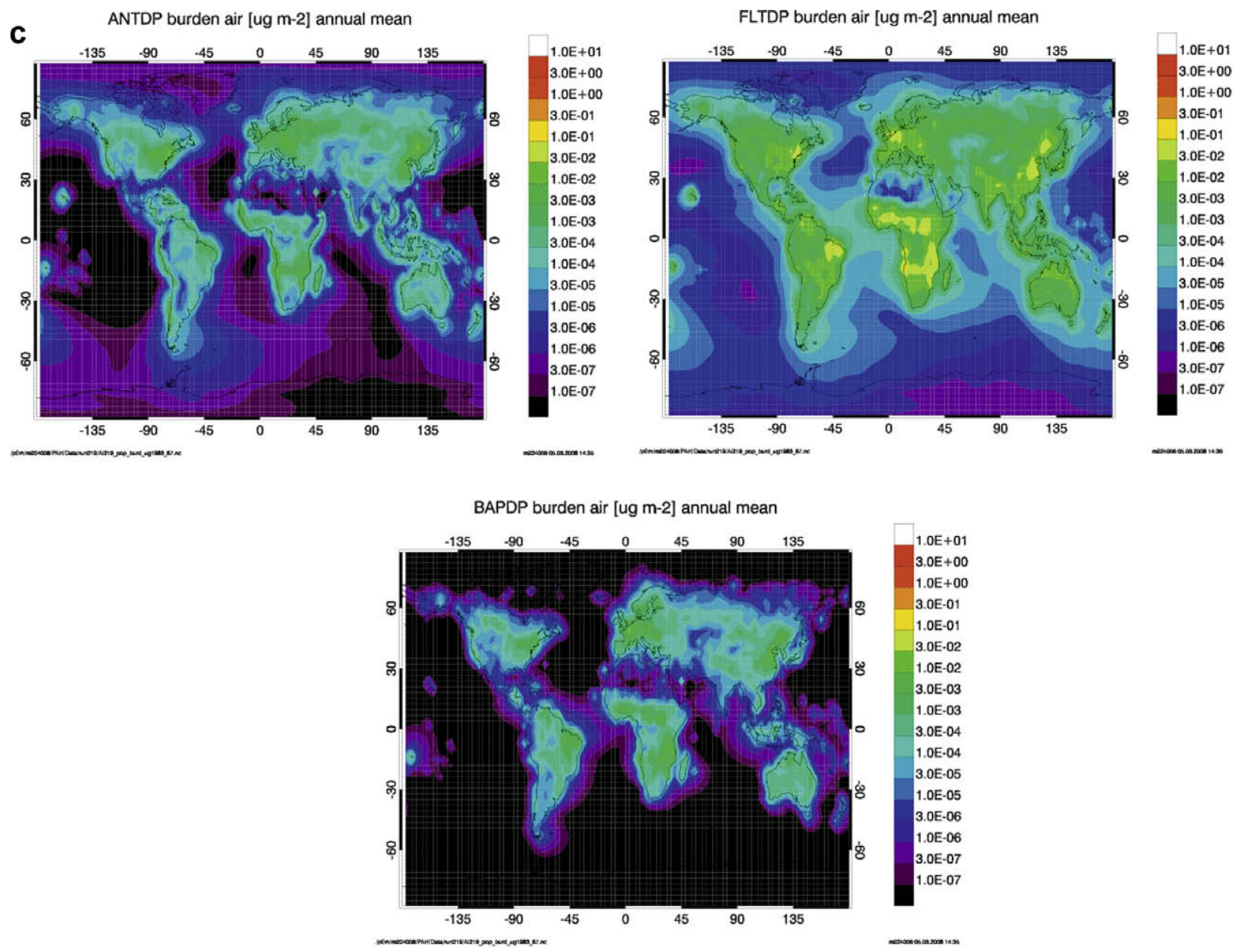

Fig. 1 (continued)

In this study, we examine three parameterisations. OB relies on the partitioning representation recommended by Lohmann and Lammel (2004), and AD uses Junge (Junge, 1977; Pankow, 1987) partitioning. Both neglect reactions between oxidants and PAHs sorbed to particles. In a third case (DP), the OB parameterisation is used for partitioning and gas-phase rate coefficients are used for reactions between particulate phase PAHs and oxidants (Table 1).

\section{Results and discussion}

Gas/particle partitioning: The influence of the choice of scenario on BAP gas/particle partitioning is small. However, under the OB scenario much higher particulate fractions, $88-89 \%$ as the global mean at ground level, are predicted for ANT and FLT than under the AD scenarios, $8-18 \%$ depending on season and substance. Geographical and vertical distributions of the particulate fractions are provided and discussed in the Supplementary material (Table S2, Figs. S4, S5). The combined adsorption to one small fraction of the aerosol (BC) and absorption to another small mass fraction $(\mathrm{OM})$ leads to higher particulate fractions than the adsorption to all surfaces $(A D)$. Because of the lack of degradation in the particulate phase $(A D, O B)$ in the high particle-bound fractions, the atmospheric lifetime of PAH is close to that of the aerosol components, i.e. 4-5 d (Stier et al., 2005). In contrast, the lifetimes under oxidant attack (in the gas-phase or in the particulate phase under the DP scenario) are in the range 1-3 h. They are highest for FLT during the day $(6 \mathrm{~h}$, assuming low troposphere mean levels of 30 ppbv $\mathrm{O}_{3}, 8 \times 10^{-5}$ ppbv $\mathrm{OH}$ during day-time and $6 \times 10^{-3} \mathrm{ppbv}$ $\mathrm{NO}_{3}$ during night-time).
Compartmental distributions: In the simulation, the substances reach a pseudo-steady state with regard to cycling between the environmental compartments within a few years (see Fig. S8 of the Fig. S8 of the Supplementary material). The resulting global distribution is quantified in Table 2.

A considerable fraction of annual emissions, $25-50 \%$, is predicted to be stored in the environmental compartments under the OB scenario, much less (1-15\%) under the AD and DP scenarios (annual means; Table 2). In all scenarios, the mass fraction of the total environmental burden stored in air is <4\%; smaller than that stored in the other compartments. Distributions are shown in Fig. 1. The atmospheric burden is highest, $2.5-3.6 \%$, under the $\mathrm{OB}$ scenario, $0.8-1.3 \%$ under the $\mathrm{AD}$ and, lowest, namely $0.3-0.8 \%$ under the DP scenario. This is the consequence of the combination of vapour pressure and degradation rate coefficients (see Table 1 ). Most of the global burden is stored in soils and on vegetation surfaces to similar amounts. Only a few percent, $\leqslant 6$, are stored in the ocean under the AD and DP scenarios, but up to $11 \%$ under the OB scenario. Again, it is the long atmospheric lifetime under this scenario which allows more of the substance to reach the oceans.

The total environmental residence times, $\tau_{\text {overall }}$, are on the order of a few days under the DP scenario, 1-8 weeks (AD scenario) and 3-6 months (OB) result (Table 2 ). The compartmental and total environmental residence times are defined as:

$$
\begin{aligned}
& \tau_{\mathrm{j}}=b_{\mathrm{j}} /\left(F_{\mathrm{em}}+F_{\mathrm{j}}\right) \\
& \tau_{\text {overall }}=b_{\text {total }} / F_{\mathrm{em}}
\end{aligned}
$$


where $b_{\text {total }}, b_{\mathrm{j}}$, denote the total environmental and compartmental burdens $(\mathrm{t})$ and $F_{\mathrm{em}}$ and $F_{\mathrm{j}}$ denote the emission and intercompartmental net mass exchange fluxes (import minus export, $\mathrm{th}^{-1}$ ), respectively.

It is found that including a degradation rate in the particulate phase comparable to the gas-phase rate (DP) has an enormous impact, it results in a difference of almost two orders of magnitude in the total burden i.e. $b_{\mathrm{DP}}<<b_{\mathrm{OB}}$. When partitioning is governed by both adsorption and absorption (to organic matter and black carbon, $\mathrm{OB}$ ) the atmospheric lifetime is longer than when determined by adsorption alone (to all aerosol particulate matter) such that $b_{\mathrm{OB}} \approx 20 \times b_{\mathrm{AD}}$ for the semivolatile PAHs and $b_{\mathrm{OB}}=1.5 \times b_{\mathrm{AD}}$ for BAP. As a consequence of different residence times, the seasonal variation of the total burden is larger under the AD and DP scenario than under the $\mathrm{OB}$ scenario: The amount of mass stored in the environment is 10-30\% higher in northern hemisphere (NH) spring than in NH autumn under the OB. This difference is $35-60 \%$ under the $\mathrm{AD}$ and $\mathrm{DP}$ scenarios.

Simulated atmospheric levels, comparison with observations: The model predicts the highest atmospheric levels of PAHs under the OB scenario and lowest under DP (in all locations), with the difference between the scenarios, for the same substance, exceeding one order of magnitude. For BAP, however, the difference of levels under OB and AD is smaller (Figs. 2 and S6). Under the various scenarios the model predicts different seasonalities: Those of ANT and FLT are dominated by the availability of radicals (summer minima) under the $A D$ and $D P$ scenarios or not pronounced $(\mathrm{OB})$, while for BAP seasonality is influenced by more parameters under all scenarios and often bimodal (late winter and late summer maxima).

Model predictions are compared with observations preferentially at remote sites, because the uncertainty and lack of seasonality in the emission estimates will affect the simulated concentrations in these sites least. ANT, FLT and BAP in air are quite well captured by the model at a European and a Canadian Arctic site, Zeppelinfjell and Alert, under the OB scenario of gas/particle partitioning, while the $\mathrm{AD}$ and $\mathrm{DP}$ scenarios strongly underestimate the PAH concentrations (Fig. 2). The agreement under OB at Zeppelinfjell is better than in a previous study (Sehili and Lammel, 2007) where only emissions in Europe and Russia were considered. Pollution at the Svalbard site is due to LRT mostly from Europe and Russia, but advection from North America can also significantly influence pollution levels (Oehme et al., 1996). The winter maxima of all PAHs at the Arctic sites, however, are underestimated with the exception of ANT at Alert, where the measured concentrations were lower in winter than in summer. The model is not expected to capture the seasonality of PAH levels as these are determined by both the variability of the climate parameters and the emission source strengths. For example, emissions from fossil fuel combustion are higher in winter (home heating) and emissions from biomass burning are higher in the dry season. As no temporal variability of the primary emissions was considered in these simulations, the seasonality is expected to be underestimated.
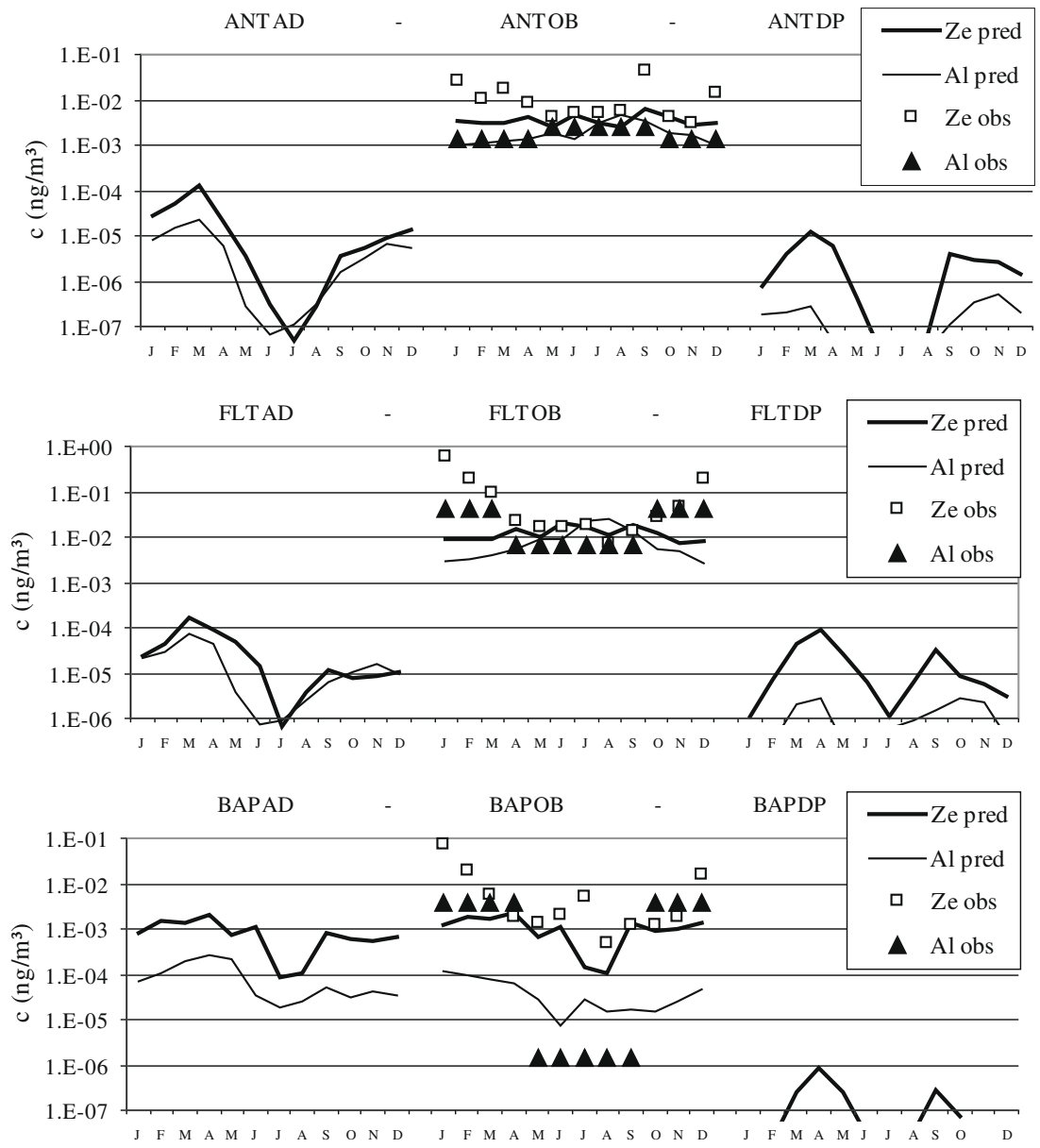

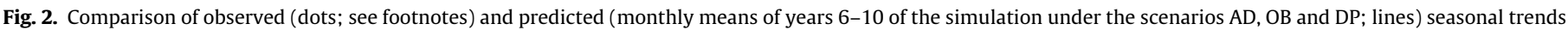

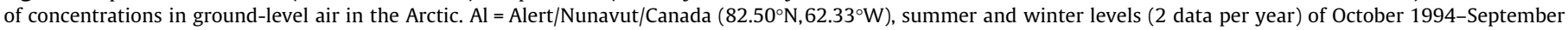
1998 (Becker et al., 1996). Ze = Zeppelinfjell/Spitsbergen/Norway (78.99N,11.88E), monthly means of 1994-1998 (EMEP, 2007). 


\section{Table 3}

Fraction of total environmental burden stored in the Arctic, $f_{\text {Arctic }}$, and in the Antarctic, $f_{\text {Antarctic }}$ and atmospheric residence time, $\tau_{\text {air }}$, of 3 PAHs under the AD, OB and DP scenarios. Mean of years 6-10 of the simulation.

\begin{tabular}{lllll}
\hline Substance & g/p-Partitioning scenario & $f_{\text {Arctic }}(\%)$ & $f_{\text {Antarctic }}(\%)$ & $\tau_{\text {air }}(\mathrm{h})$ \\
\hline ANT & AD & 2.9 & 0.22 & 1.9 \\
& OB & 12.8 & 0.82 & 121 \\
& DP & 1.6 & 0.05 & 0.31 \\
FLT & AD & 2.5 & 0.53 & 2.8 \\
& OB & 11.5 & 1.38 & 149 \\
& DP & 1.8 & 0.08 & 1.1 \\
BAP & AD & 4.9 & 0.29 & 16 \\
& OB & 4.6 & 0.19 & 48 \\
& DP & 0.5 & $<0.001$ & 0.17 \\
\hline
\end{tabular}

Results for other remote (tropics, sub-tropics, northern mid latitudes) and rural (mid latitudes) sites are compared and discussed in the Supplementary material. Agreement between predicted and observed levels (annual means) is found almost exclusively under the OB scenario. The only exception is the overprediction of ANT and FLT in the Great Lakes area (see SI). Seasonality, furthermore, is nowhere captured better under the $\mathrm{AD}$ scenario than under $\mathrm{OB}$. In conclusion, the comparison between predicted and observed PAH concentrations in air is the most consistent with the OB scenario. The results suggest that $\mathrm{OB}$ does not overestimate the importance of other types of partitioning than unspecific adsorption to the surface of particles. That is, the evidence supports the perception that $\mathrm{PAH}$ is significantly less degradable in the particle-bound state than in the gas-phase, and that there is strong sorption to $\mathrm{BC}$ and $\mathrm{OM}$ in aerosols. Partitioning to the particulate phase of the atmospheric aerosol through adsorption alone cannot explain the ANT and FLT levels observed on a global scale.

It has been shown in laboratory experiments that, at least for the case of ozone, only part of the PAH on graphite particles is accessible to the oxidant (Perraudin et al., 2007). Our results support the theory that absorption significantly influences gas-particle partitioning and suggest that PAHs absorbed in the organic matrix of particulate matter is shielded from the gas-phase, because assuming accessability for oxidants (DP scenario) leads to predictions far off reality. Laboratory measurements using carbon-rich model particulate matter with absorptive properties could provide complementary evidence.

Deposition and volatilisation fluxes: Our results suggest that large continental and oceanic regions are, depending on the season, regions which have a net volatilizing flux of semivolatile PAHs, but to a limited extent also BAP under the $\mathrm{OB}$, and even more under the AD scenario. Global budgets and distributions of net-deposition fluxes are shown in the Supplementary material (Table S3a, Fig. S7). These results emphasize the multi-hopping potential of semivolatile POPs suggested in a previous study (Sehili and Lammel, 2007). The budgeting for the Arctic and Antarctic regions shows that the studied PAHs are not accumulating there (see Table $\mathrm{S} 3 \mathrm{~b}$ ). These budgets should be considered preliminary, however, as cycling in ice is neglected in the model and both deposition and volatilisation fluxes will deviate in ice-covered areas. This should be addressed in the future by improved model tools.

Input to the Arctic: Under the $\mathrm{AD}$ and $\mathrm{OB}$ scenarios the studied PAHs are predicted to undergo regional transport and reach high latitudes. The highest fractions of the PAHs studied are expected to reach the Arctic and Antarctic under the OB scenario (ANT, FLT) or under the AD scenario (BAP, then only slightly more than under the $\mathrm{OB}$ scenario; Table 3). Advection to the Arctic is predicted from Europe, while not reaching it from America. The reason is unclear. However, meridional transports in high latitudes could be underestimated by the model over land (American Arctic) as opposed to over sea (European Arctic), because snow-covered land is represented as 'soil' in the model and residence times of substances with low water solubility in soil are higher than in snow. The LRT is most effective for ANT and FLT under the OB, and for BAP under the AD scenario. These results reflect the atmospheric residence times, $\tau_{\text {air }}$ (Table 3 ), and the total environmental residence times, $\tau_{\text {overall }}$ (Table 2 ). LRT under the DP scenario is limited and the emission patterns are largely preserved (Fig. 1), because atmospheric lifetimes under this scenario are too short, 0.2-1 h.

In the case of semivolatile organic compounds which resist degradation in ground compartments long-range atmospheric transport can occur as single-hop or multi-hop (re-volatilisation; Wania and Mackay, 1993; Semeena and Lammel, 2005). The existence of large regions with seasonal net-volatilisation (Fig. S7) emphasises the multi-hopping behaviour of the PAHs studied. However, the results of the simulation suggest that LRT including multi-hopping is not effective enough to create accumulation in the Arctic in the sense of 'global distillation': The ratio of the deposition fluxes, $F_{\text {dep_Arctic }} / F_{\text {dep_global, }}$ does not exceed the ratio of the respective areas $(8 \%)$. In the case of the semivolatile PAHs, ANT and FLT, with $F_{\text {dep_Arctic }} / F_{\text {dep_global }} \approx 5$ and $\approx 3 \%$, respectively, inputs under OB come close to the value of the ratio of the areas. (see Table S3b in the Supplementary material).

LRT potential and environmental residence time ( $\tau_{\text {overall }}$, persistence) are often used to characterize the hazard chemicals impose onto the environment (Scheringer, 1996; Leip and Lammel, 2004). We compare PAHs (from this study) with organochlorine pesticides (OCPs), studied recently using the same model (1980 emis-
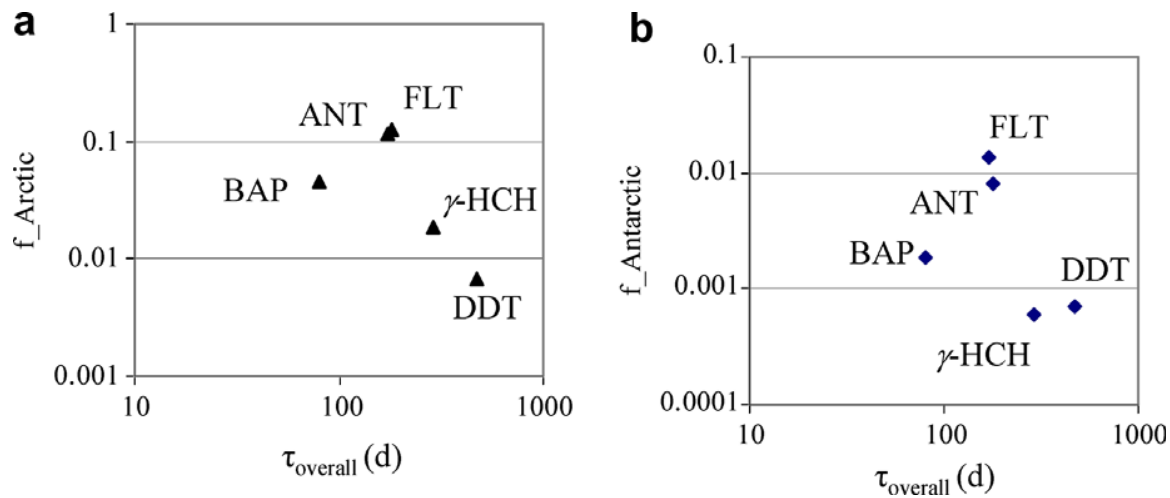

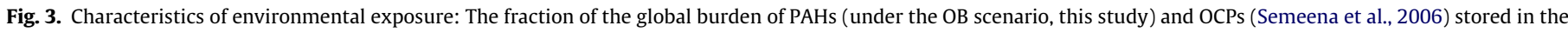
Arctic, $f_{\text {Arctic }}(\mathrm{a})$, and Antarctic, $f_{\text {Antarctic }}(\mathrm{b})$ vs. total environmental residence time, $\tau_{\text {overall }}(\mathrm{h})$. 
sions; Semeena et al., 2006) and using the fractions stored in polar regions as indicator of the LRT potential (Fig. 3). Interestingly, these fractions are about a factor of $\approx 10$ and $\approx 3$ higher for the semivolatile PAHs and BAP, respectively, than for DDT and $\gamma-\mathrm{HCH}$ despite the shorter $\tau_{\text {overall }}$. This difference can hardly be explained by differences in the emission spatial distributions, as these are quite similar, or by $\tau_{\text {air }}$, because the five substances rank similar in $\tau_{\text {air }}$ and $\tau_{\text {overall }}$ (among the PAHs this is caused by identical $\tau_{\text {soil }}, \tau_{\text {vegeta- }}$ tion and $\tau_{\text {ocean }}$, see Table 1 ). It is, instead, a consequence of the way that the species are split-up upon release (mode of entry): PAHs were released $100 \%$ into the air, but OCPs were released $20 \%$ on soil and $80 \%$ on vegetation. This potentially strong influence of the mode of entry on the LRT potential had been emphasized before (e.g. Wania, 2003; Lammel et al., 2007). The ranking of substances according to their LRT potential differs between the Arctic and the Antarctic, this can be explained by substance interactions with different patterns of land/ocean, oxidants, precipitation, etc. The range of values of $f_{\text {Arctic }}$ of the PAHs, $4.6-12.8 \%$, exceeds those based on a generic zonal multimedia model (Wania, 2003), $\approx 1-$ $2.5 \%$, but the ranking of the three substances with regard to $f_{\text {Arctic }}$ is the same.

\section{Acknowledgment}

This research was supported by the German Research Foundation (DFG). We thank Irene Stemmler for technical help and Ivan Holoubek for sharing unpublished data.

\section{Appendix A. Supplementary material}

Supplementary data associated with this article can be found, in the online version, at doi:10.1016/j.chemosphere.2009.02.017.

\section{References}

Becker, S., Halsall, C.J., Tych, W., Hung, H., Attewell, S., Blanchard, P., Li, H., Fellin, P., Stern, G., Billeck, B., Friesen, S., 1996. Resolving the long-term trends of polycyclic aromatic hydrocarbons in the Canadian Arctic atmosphere. Environ. Sci. Technol. 40, 3217-3222.

Bond, T.C., Streets, D.G., Yarber, K.F., Nelson, S.M., Woo, J.H., Klimont, Z., 2004. A technology-based global inventory of black and organic carbon emissions from combustion. J. Geophys. Res. 109, D14203. doi:10.1029/2003JD003697.

Bouchez, M., Blanchet, D., Haeseler, F., Vandecasteele, J.P., 1996. Les hydrocarbures aromatiques polycycliques dans l'environnement - Propriétés, origines, devenir. Rev. I. Fr. Petrole 51, 407-419.

Cotham, W.E., Bidleman, T., 1995. Polycyclic aromatic hydrocarbons and polychlorinated biphenyls in air at an urban and a rural site near Lake Michigan. Environ. Sci. Technol. 29, 2782-2789.

Dachs, J., Eisenreich, S.J., 2000. Adsorption onto aerosol soot carbon dominates gas particle partitioning of polycyclic aromatic hydrocarbons. Environ. Sci. Technol. 34, 3690-3697.

Dickhut, R.M., Gustafson, K.E., 1995. Atmospheric inputs of selected polycyclic aromatic hydrocarbons and polychlorinated biphenyls to southern Chesapeake Bay. Mar. Pollut. Bull. 30, 385-396.

EMEP - Co-operative programme of the monitoring and evaluation of the longrange transmissions of air pollutants in Europe, 2007. <http://www.nilu.no/ projects/ccc/emepdata.html> (accessed 6.5.07).

Estève, W., Budzinski, H., Villenave, E., 2006. Relative rate constants for the heterogeneous reactions of $\mathrm{NO}_{2}$ and $\mathrm{OH}$ radicals with polycyclic aromatic hydrocarbons adsorbed on carbonaceous particles. Part 2: PAHs adsorbed on diesel particulate exhaust SRM 1650a. Atmos. Environ. 40, 201-211.

Feichter, J., Kjellström, E., Rodhe, H., Dentener, F., Lelieveld, J., Roelofs, G., 1996 Simulation of the tropospheric sulfur cycle in a global climate model. Atmos. Environ. 30, 1693-1707.

Fernández, P., Grimalt, J.O., Vilanova, R.M., 2002. Atmospheric gas/particle partitioning of polycyclic aromatic hydrocarbons in high mountain regions of Europe. Environ. Sci. Technol. 36, 1162-1168.

Finizio, A., Mackay, D., Bidleman, T., Harner, T., 1997. Octanol-air partition coefficient as a predictor of partitioning of semi-volatile organic chemicals to aerosols. Atmos. Environ. 31, 2289-2296.

Finlayson-Pitts, B.J., Pitts, J.N., 2000. Chemistry of the Upper and Lower Atmosphere: Theory, Experiments, Application. Academic Press, San Diego.

Franklin, J., Atkinson, R., Howard, P.H., Orlando, J.J., Seigneur, C., Wallington, T.J. Zetzsch, C., 2000. Quantitative determination of persistence in air. In: Klečka, G. et al. (Eds.), Criteria for Persistence and Long-Range Transport of Chemicals in the Environment. SETAC Press, Pensacola, USA

Galarneau, E., Bidleman, T.F., Blanchard, P., 2006. Seasonality and interspecies differences in particle/gas partitioning of PAHs observed by the integrated atmospheric deposition network (IADN). Atmos. Environ. 40, 182-197.

Harner, T., Bidleman, T.F., 1998. Measurement of octanol-air partitioning coefficients for polycyclic aromatic hydrocarbons and polychlorinated naphthalenes. J. Chem. Eng. Data 43, 40-46.

Horowitz, L.W., Walters, S., Mauzerall, D.L., Emmons, L.K., Rasch, P.J., Granier, C., Tie, X., Lamarque, J.-F., Schultz, M.G., Tyndall, G.S., Orlando, J.J., Brasseur, G.P., 2003. A global simulation of tropospheric ozone and related tracers: description and evaluation of MOZART, version 22. J. Geophys. Res. 108, 4784. doi:10.1029/ 2002JD002 853.

Junge, C.F., 1977. Fate of pollutants in the air and water environment. In: Suffet, I.H. (Ed.), Basic Considerations about Trace Constituents in the Atmosphere as Related to the Fate of Global Pollutants. Wiley, New York, pp. 7-25.

Klöpffer, W., Wagner, B., 2007. Atmospheric Degradation of Organic Substances Data for Persistence and Long-Range Transport Potential. Wiley-VCH, Weinheim, Germany. p. 243

Lammel, G., Klöpffer, W., Semeena, V.S., Schmidt, E., Leip, A., 2007. Multicompartmental fate of persistent substances: comparison of predictions from multi-media box models and a multicompartment chemistry-atmospheric transport model. Environ. Sci. Pollut. R 14, 153-165.

Leip, A., Lammel, G., 2004. Indicators for persistence and long-range transport potential as derived from multicompartment chemistry-transport modelling. Environ. Pollut. 128, 205-221.

Lohmann, R., Lammel, G., 2004. Adsorptive and absorptive contributions to the gas particle partitioning of polycyclic aromatic hydrocarbons: State of knowledge and recommended parameterization for modelling. Environ. Sci. Technol. 38, 3793-3803.

Macdonald, R.W., Barrie, L.A., Bidleman, T.F., Diamond, M.L., Gregor, D.J., Semkin, R.G., Strachan, W.M., Li, Y.F., Wania, F., Alaee, M., Alexeeva, L.B., Backusand, S.M., Bailey, R., Bewers, J.M., Gobeil, C., Halsall, C.J., Harner, T., Hoff, J.T., Jantunen, L.M.M., Lockhart, W.L., Mackay, D., Muir, D.C.G., Pudykiewicz, K.J., Reimer, K.J., Smith, J.N., Stern, G.A., Schroeder, W.H., Wagemann, R., Yunker, M.B., 2000. Contaminants in the Canadian Arctic: 5 years of progress in understanding sources, occurrence and pathways. Sci. Total Environ. 254, 93-234.

McLachlan, M., 1999. Framework for the interpretation of measurements of SOCs in plants. Environ. Sci. Technol. 33, 1799-1804.

Oehme, M., Haugen, J.E., Schlabach, M., 1996. Seasonal changes and relations between levels of organochlorines in Arctic ambient air: first results of an allyear-round monitoring program at Ny-Ålesund, Svalbard, Norway. Environ. Sci. Technol. 30, 2294-2304.

Pankow, J.F., 1987. Review and comparative analysis of the the theory of partitioning between the gas and aerosol particulate phases in the atmosphere. Atmos. Environ. 21, 2275-2283.

Perraudin, E., Budzinski, H., Villenave, E., 2007. Kinetic study of the reactions of ozone with polycyclic aromatic hydrocarbons adsorbed on atmospheric model particles. J. Atmos. Chem. 56, 57-82.

Pöschl, U., Letzel, T., Schauer, C., Niessner, R., 2001. Interaction of ozone and water vapor with spark discharge soot aerosol particles coated with benzo[a]pyrene: $\mathrm{O}_{3}$ and $\mathrm{H}_{2} \mathrm{O}$ adsorption, benzo[a]pyrene degradation, and atmospheric implications. J. Phys. Chem. A 105, 4029-4041.

Prevedouros, K., Jones, K.C., Sweetman, A.J., 2005. Modelling the fate and seasonality of polycyclic aromatic hydrocarbons in the United Kingdom atmosphere. Chemosphere 56, 195-208.

Roeckner, E., Stier, P., Feichter, J., Kloster, S., Esch, M., Fischer-Bruns, I., 2006. Impact of carbonaceous aerosol emissions on regional climate change. Clim. Dynam. 27. doi:10.1007/s00382-006-0147-3.

Schauer, C., Niessner, R., Pöschl, U., 2003. Polycyclic aromatic hydrocarbons in urban air: decadal and seasonal trends, chemical degradation, and sampling artefacts. Environ. Sci. Technol. 37, 2861-2868.

Scheringer, M., 1996. Persistence and spatial range as endpoints of an exposurebased assessment of chemicals. Environ. Sci. Technol. 30, 1652-1659.

Sehili, A.M., Lammel, G., 2007. Global fate and distribution of polycyclic aromatic hydrocarbons emitted from Europe and Russia. Atmos. Environ. 41, 83018315.

Semeena, V.S., Lammel, G., 2005. The significance of the grasshopper effect on the atmospheric distribution of persistent organic substances. Geophys. Res. Lett. 32, L07804. doi:10.1029/2004GL022229.

Semeena, V.S., Feichter, J., Lammel, G., 2006. Impact of the regional climate and substance properties on the fate and long-range transport of persistent organic pollutants - examples of DDT and $\gamma$-HCH. Atmos. Chem. Phys. 6, 1231-1248.

Stier, P., Feichter, J., Kinne, S., Kloster, S., Vignati, E., Wilson, J., Ganzeveld, L., Tegen, I., Werner, M., Schulz, M., Balkanski, Y., Boucher, O., Minikin, A., Petzold, A., 2005. The aerosol-climate model ECHAM5-HAM. Atmos. Chem. Phys. 5, 11251156.

Sweetman, A.J., dalla Valle, M., Prevedouros, K., Jones, K.C., 2005. The role of soil organic carbon in the global cycling of persistent organic pollutants: interpreting and modelling field data. Chemosphere 60, 959-972.

Tsapakis, M., Stephanou, E.G., 2003. Collection of gas and particle semi-volatile organic compounds: use of an oxidant denuder to minimize polycyclic aromatic hydrocarbons degradation during high-volume air sampling. Atmos. Environ. 37, 4935-4944.

Tsapakis, M., Stephanou, E.G., 2005. Occurrence of gaseous and particulate polycyclic aromatic hydrocarbons in the urban atmosphere: study of sources 
and ambient temperature effect on the gas/particle concentration and distribution. Environ. Pollut. 133, 147-156.

Wania, F., 2003. Assessing the potential of persistent organic chemicals for longrange transport and accumulation in polar regions. Environ. Sci. Technol. 37, 1344-1351.

Wania, F., Mackay, D., 1993. Global fractionation and cold condensation of low volatility organic chlorine compounds in polar regions. Ambio 22, 10-18.
WHO - World Health Organization, 2003. Health Risks of Persistent Organic Pollutants from Long-Range Transboundary Air Pollution. WHO Regional Office for Europe, Copenhagen, p. 252

Zhang, Y., Tao, S., Cao, J., Coveney, R.M., 2007. Emission of polycyclic aromatic hydrocarbons in China by county. Environ. Sci. Technol. 41, 683-687. 